\title{
GEOGRAPHIC INFORMATION SYSTEMS (GIS) IN PUBLIC LIBRARY ASSESSMENT
}

\author{
Bradley Wade Bishop \\ Assistant Professor \\ School of Library and Information Science \\ University of Kentucky \\ 352 Little Library Building \\ Lexington, KY 40506-0224 \\ Telephone 859.257.3970 \\ E-mail: wade.bishop@uky.edu \\ Lauren H. Mandel \\ Research Coordinator \\ Information Use Management \& Policy Institute \\ 010 Louis Shores Building \\ 142 Collegiate Loop \\ P.O. Box 3062100 \\ Tallahassee, FL 32306-2100 \\ Telephone 850.645.5683 \\ E-mail: $\underline{\text { lmandel@fsu.edu }}$ \\ Charles R. McClure \\ Frances Eppes Professor, and Director \\ Information Use Management \& Policy Institute \\ 010 Louis Shores Building \\ 142 Collegiate Loop \\ P.O. Box 3062100 \\ Tallahassee, FL 32306-2100 \\ Telephone 850.645.5683 \\ E-mail: cmcclure@lis.fsu.edu
}

\begin{abstract}
This paper details three projects utilizing geographic information systems (GIS) in the assessment of public libraries. The benefits of GIS include the abilities to generate maps to convey more information than through other means and to allow for spatial analysis of library services. This paper includes specific examples of uses implemented by the authors. GIS allowed the authors to display data related to library service and identify various disparities across service areas. In addition, this paper discusses practical issues of GIS for library researchers and practitioners based upon the knowledge gained through the development of the three GIS projects discussed here.
\end{abstract}

Keywords: Geographic information systems, Public libraries, Evaluation, Library services, Information policy 


\section{Introduction}

Geographic Information Systems (GIS) are "computer-based tool[s] for the input, storage, management, retrieval, update, analysis and output of information" (United Nations, 2000, p. 121). For public libraries, GIS have been used to analyze and display data in predominantly two different ways (1) analyzing service area populations and (2) managing facilities and collections (Bishop \& Mandel, 2010). For example, to analyze service area populations, user demographics may be entered into GIS and projected over street maps. Then, a public library can see where its service population lives in relation to library branches. Similar analyses may be conducted for managing facilities and collections, albeit at different granularity than viewing a countywide spread of user populations. Instead of mapping user demographics at a countywide, street, or other level outside the library, GIS can be used to analyze in-library use data and occupancy of library study space by mapping locations of users and materials within the facility at samples times in order to assess those library services.

A literature review performed in 2010 of library research that uses GIS as a tool to assess and analyze library services discusses 34 articles indexed in the Library Literature and Information Full Text and LISTA Library, Information Science and Technology Abstracts databases (Bishop \& Mandel, 2010). One of the limitations of that literature review was the unknown numbers of library consultation projects that do not disseminate knowledge gained through the use of GIS via academic publications. Perhaps consultation projects do not publish because they might lack rigorous methodology required for peer-reviewed publications or, simply, their clients do not wish to make findings public for privacy purposes and competitive advantage. In an effort to fill this void, this paper shares knowledge gained from three previously unpublished projects utilizing GIS, in hopes of adding to the foundation of library research in the GIS area.

The majority of research articles found in the literature review provided only the end result of analysis and the end products (i.e., maps) of their projects with little discussion of methods and strategies to assist future projects or duplicate studies (Bishop \& Mandel, 2010). A potential reason that prior GIS research in library and information science (LIS) lacks discussion of specific methodological issues and strategies within may be due to the difficulty of explaining cartographic and geographic principles to non-GIS expert readers. This paper presents a more lengthy discussion on methodological, cost, educational, and political issues for the use of GIS in LIS as well as introducing next steps, such as education and training of LIS researchers, educators, and stakeholder groups.

GIS applications in LIS research are slowly developing, but as the literature review indicates (Bishop \& Mandel, 2010 ), they are expanding. This paper is intended to contribute to the literature on uses of GIS in LIS research by providing overviews of three research projects in which the Information Use Management and Policy Institute (Information Institute (www.ii.fsu.edu/) incorporated GIS as part of multi-method research strategies. The projects are described with some detail as to how GIS was used to analyze and visualize data, but the explanations are intended to be understandable by researchers with little GIS background. In addition, this paper describes some of the complications and challenges to consider when 
designing research to include GIS methods and makes recommendations for how GIS applications can be better incorporated into LIS research.

\section{Utilizing GIS in Library Assessment}

The Information Institute conducts research on a variety of topics that include the interaction of users with information products, services, policies, technologies, and organizations, and information policy research on current issues at every level of government related to public access, privacy, records management, and use of information in electronic forms. The Information Institute places a particular emphasis on the planning and evaluation of networked and other information services through analysis and evaluation of the impact of systems from policy and user perspectives. The Information Institute decided to explore the use of GIS as a tool for data storage, analysis, and visualization based on its potential benefits to generate maps and allow for spatial analysis. The technology was used as a tool to add another dimension to Information Institute program evaluations.

Information Institute program evaluations and other research projects are conducted using a multi-method research strategy (Bertot, McClure, \& Ryan, 2001). Although multi-method research can require more time, money, and effort than singular research methods, the Information Institute feels that the ability to gain a more comprehensive view of a research problem and the ability to check the validity of each method by integrating data from multiple methods outweigh any extra effort required on the part of the research team. Accordingly, the Information Institute decided to incorporate GIS as an analytical and visualization tool to strengthen the findings and dissemination of its research.

GIS is a tool that allows geospatial analysis and display, that is, analysis and display of phenomena that include consideration of the physical location of the phenomena. For example, LIS research might investigate the cost effectiveness of a new library branch location by doing quantitative analyses of the population demographics, circulation statistics, and other data from the neighborhood, as well as surveying or interviewing library users about their opinions of the new location. Reporting that data in tables allows comparison of quantitative data, and including quotes from the interviews provides some contextual information, but neither of these reporting options provides as much flexibility in analysis and display as GIS. By using GIS to analyze and display this example data, an LIS researcher could compare circulation data per capita in different neighborhoods to determine the neighborhoods with the highest numbers of underserved populations as potential sites for a new branch library, and the researcher could display the findings on an easy-to-read map making the data more easily understood by librarians, funding boards, and library users. This is just one example of the benefits of utilizing GIS as a tool to complement methods in LIS research. The descriptions of the Information Institute projects that incorporated GIS provide other such examples.

This paper reviews three projects utilizing GIS at the Information Institute and discusses the practical lessons learned through the iterative use of GIS on recent projects. The projects used GIS to: (1) analyze the locations of users of a statewide chat reference consortium, (2) create a visualization of national public library data, and (3) compare Internet connection speeds and costs across regions of Florida to demonstrate the need for increased Internet connection speeds and reduced costs of specific public libraries. The following sections of this paper 
describe the strategies used and the practical lessons learned from three projects, in chronological order. This paper spares readers the minute details of the technology and methodology behind GIS; however, readers who are interested in more background on the concepts and techniques of GIS should read Prentice Hall's Series in Geographic Information Science or browse GIS journals, such as the International Journal of Geographic Information Science. The paper then concludes with discussion of issues relevant for future use of GIS in library research. For more detail on the methodologies employed in these three projects, see Mon, Bishop, McClure, McGilvray, Most, Milas, \& Snead (2007, 2009) (for analysis of the statewide chat reference consortium), Bertot, McClure, Barton, Thomas, \& McGilvray (2007) (for visualization of national public library data), and McClure, Ryan, Mandel, Snead, \& Bishop (2009) (for comparison of Internet connection speeds and costs across Florida).

\section{Who's Asking? Geography \& Demographics of Florida's Ask A Librarian Service}

As part of a larger evaluation of the Florida Electronic Library (FEL,

http://www.flelibrary.org), the Information Institute analyzed the geographic dispersion of the users of FEL's Ask a Librarian chat reference service. Ask a Librarian provides Florida residents with live virtual reference services via local library customized websites 84 hours a week. The service collects data on the library entry portal for each user and each user's Internet protocol (IP) address, which may be geocoded. Geocoding is the process by which latitude and longitude coordinates are assigned to addresses to map them via GIS. To map the geographic dispersion of the users of Ask a Librarian, the users' entry portals and IP addresses from 1,859 chat transcripts from August 2006 were geocoded by corresponding the physical address to the user's entry portal and using IP2Location (http://www.ip2location.com) to determine the approximate location of the users' actual location via an IP address.

After plotting all the coordinates as they appeared individually on a state map, the study team determined that nearly two thousand individual points did not reveal a trend, so the team decided to aggregate the data to the county level in order to compare questioning activity for Florida's 67 counties. This representation left some counties empty, so the study team determined that the county level depiction of the service also was problematic because visualizing the state with several counties without data points did not paint a picture of statewide Ask a Librarian usage. To further aggregate the data, the study team merged the points to show the questioning activity at the level of the state's six Multi-type Library Cooperatives (MLCs), which represent large areas of the state. See Figure 1 for a visualization of Florida's six MLCs: Panhandle Library Access Network, Inc. (PLAN), Northeast Florida Library Information Network (NEFLIN), Central Florida Library Cooperative (CFLC), Tampa Bay Library Consortium (TBLC), Southwest Florida Library Network, Inc. (SWFLN), and Southeast Florida Library Information Network, Inc. (SEFLIN). 


\section{Florida's Multi-type Library Cooperatives}

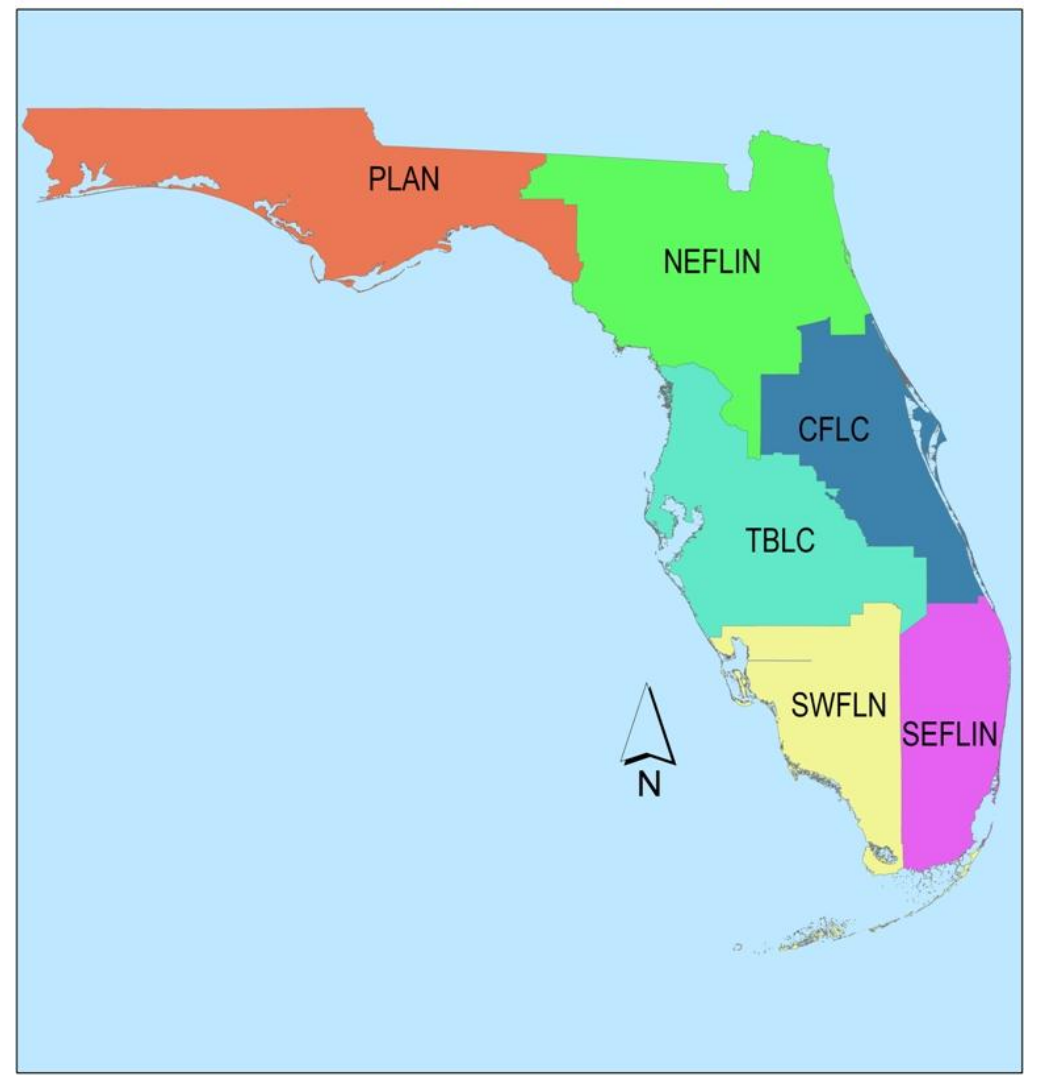

Figure 1. Florida's MLCs.

Another challenge the study team faced was how to map entry points that did not correspond to physical locations. For example, the Florida Virtual School and main entry page for Ask a Librarian have no corresponding geography; they are virtual entry portals that may be accessed from any physical location anywhere in the world. Therefore, the entry places of virtual places were mapped to places other than Florida. To minimize confusion about the mapped locations of these virtual entry places, the study team selected a random, oddly-shaped island to serve as the representative location for these virtual places because its shape differed greatly from the shape of Florida. Figure 2 depicts entry points to Ask a Librarian by MLC to reveal the dispersion of users across Florida. 


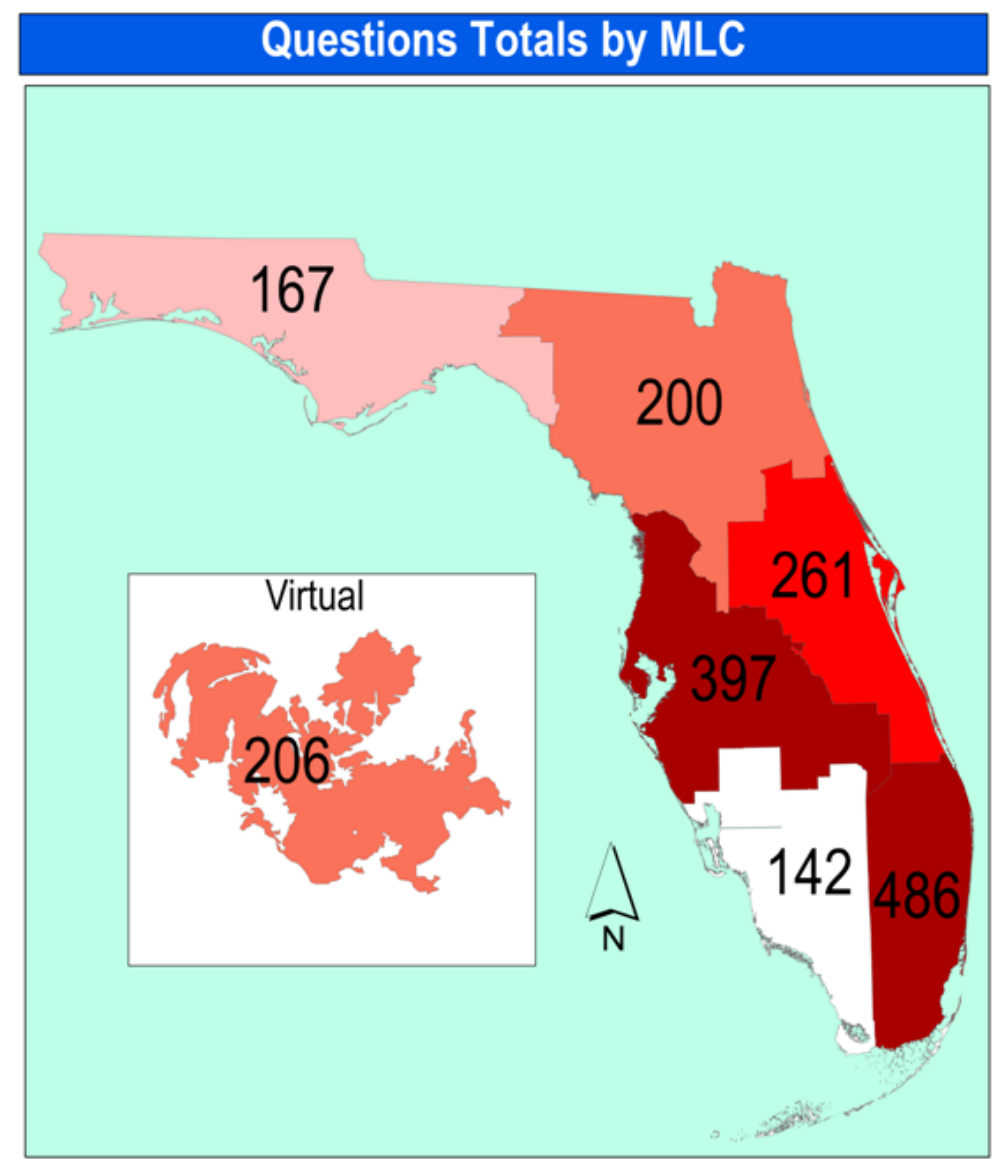

Figure 2. Chat User Entry Portals by MLC.

SEFLIN and TBLC received the most activity in August 2006, $n=486$ and $n=397$, respectively. These happen to be the most populated areas of the state, including the Tampa Bay and Fort Lauderdale-Miami metropolitan areas. Normalizing data by population could have been performed to produce maps displaying use per capita, but these would have been misleading due to the varying numbers of participating libraries in each MLC, the number of users asking questions to librarians outside of their MLCs, and the unknown population of virtual users. In concert, these considerations complicated normalization of the data so, rather than produce maps that might misrepresent per capita usage, the Information Institute decided not to normalize the data. More detailed discussion and maps may be found in that project's final report and a related article (Mon et al., 2007; Mon et al., 2009). The practical lessons learned from this exploratory use of GIS in displaying user data include:

- IP address geocoding is problematic,

- Politics of disparities in a consortium present challenges, and

- Librarians like maps.

Inherent flaws in geocoding IP addresses include (1) some Internet service providers (ISPs) do not have geographic information related to every IP address, (2) users may anonymize their IP 
addresses making it impossible to identify their physical locations, and (3) there is no way to tell when those issues are occurring. In some instances where there is no physical address linked to the IP, IP addresses may be geolocated to the ISP rather than their own local area. For example, in the Ask a Librarian project, Virginia locations appeared often, due to the locations of American Online (AOL) and Verizon operations, even though the individual users were more likely in Florida. In addition, Florida users from many colleges, universities, and community colleges may be distance learners, yet access the service through the university library's website, in which case the entry point misrepresents the users' actual physical addresses. Perhaps, these obstacles may be overcome via other methods for geolocating the users, but the Information Institute determined that mapping users by IP addresses involved too many complications to continue to use as a tool in this particular project.

Another practical lesson learned from this project relates to the political context of statewide assessments, which should not be overlooked with any mapping activity. In this instance, the statewide service had many librarians from around the state staffing it and residents from all over Florida and other locations in the U.S. using it. Displaying the inequity of either users or those staffing the service in a consortium revealed pockets of heavy use and absence of any users, both of which can raise questions about the equity of libraries staffing a statewide service where they may be assisting users they are not statutorily supposed to serve.

For the users' maps, the results could have indicated where marketing efforts had been more successful, where potential users could be found, or where the areas with greater populations are in the state. At the very least, these maps gave a snapshot of the geographic dispersion of users - again, only state residents should access this service, but users appeared in several states. For the staffing maps, members of the consortium could see that some libraries' users ask more questions than others. This could open up other political issues with some areas of the state providing more support and receiving less help with their own users. As was discussed, aggregating data at different levels may mask these inequities of both staffing and geographic dispersion of users.

The Information Institute continued exploring the mapping and analysis of data with GIS based upon positive feedback from librarians. Viewing data in space gave the virtual reference service a sense of the actual users served around the state. Further analysis could be conducted to inform future staffing and marketing decisions. Regardless of spatial analyses, librarians wanted to see maps with a range of information being presented. Unlike the disparities that the statewide consortium wanted to avoid highlighting, the GIS project discussed next included public libraries from the entire United States with noticeably lower numbers of workstations that wanted to depict the disparities between states in order to support the argument for improved connectivity.

\section{Public Libraries and the Internet 2007: Survey Results and Findings}

The longest-running study of Internet connectivity in public libraries began in 1994 in order to assist library directors and library IT staff benchmark and advocate for technology resources (Bertot \& McClure, 1998a, 1998b, 2000, 2002; Bertot et al., 2007; Bertot, McClure, \& Fletcher, 1997; Bertot, McClure, \& Jaeger, 2004, 2006; Bertot, McClure, Wright, Jensen, \& Thomas 2008, 2009; Bertot, McClure, \& Zweizig, 1996; McClure, Bertot, \& Zweizig, 1994). 
The data are also of importance for policymakers at local, state, and federal levels. In 2007, the study team used GIS to analyze the data and demonstrate the potential of spatial analysis by displaying the data in alternate views than tables alone. Many states had high enough response rates for the Information Insitute to report state level findings. For these states, survey response data were joined to state shapefiles in GIS software so the team could create maps displaying the data for these states. The data chosen for mapping included the average number of public access workstations, bandwidth, and wireless connectivity in public libraries.

Maps concerning public library connectivity speeds demonstrated that only three states -Arizona, Connecticut, and Maryland - provided patrons with an average of faster than a T1 connection speed (a T1 connection speed equates to 1.5 megabits per second, or Mbps). Also, two states - Iowa and Wyoming - offered patrons an average connection speed slower than 769 kilobits per second, or kbps (Bertot et al., 2007, p. 37). For survey questions collecting interval data, the range of connectivity speeds representing the majority of responses for each state was used to depict each state's connectivity. For example, the majority of respondents from Maryland stated they provide a T1 or greater connection speed and therefore the state was assigned the $\mathrm{T} 1$ range for display.

Figure 3 displays the results for the average number of total public access workstations per library outlet, by state. For data collected at the ordinal scale, averages could be calculated. That is to say, each library responding to the survey provided a specific (i.e., ordinal) number of workstations, as opposed to the responses to connectivity questions that fell into prescribed ranges (or intervals) from the survey questions. These maps allowed comparisons to be made quickly at the state level. Although the mean of workstations for states with large numbers of small libraries would be lower, the survey weights responses from rural, suburban, and urban libraries based on their metropolitan status code to provide representative data from each state. This is done the same way for each state and the mean reflects the state averages; more detail on the survey's sampling and weighting methods are available in the reports. For example, Figure 3 clearly shows the states with higher averages of public access workstations in bright red, while states with lower averages of public access workstations are in white. 


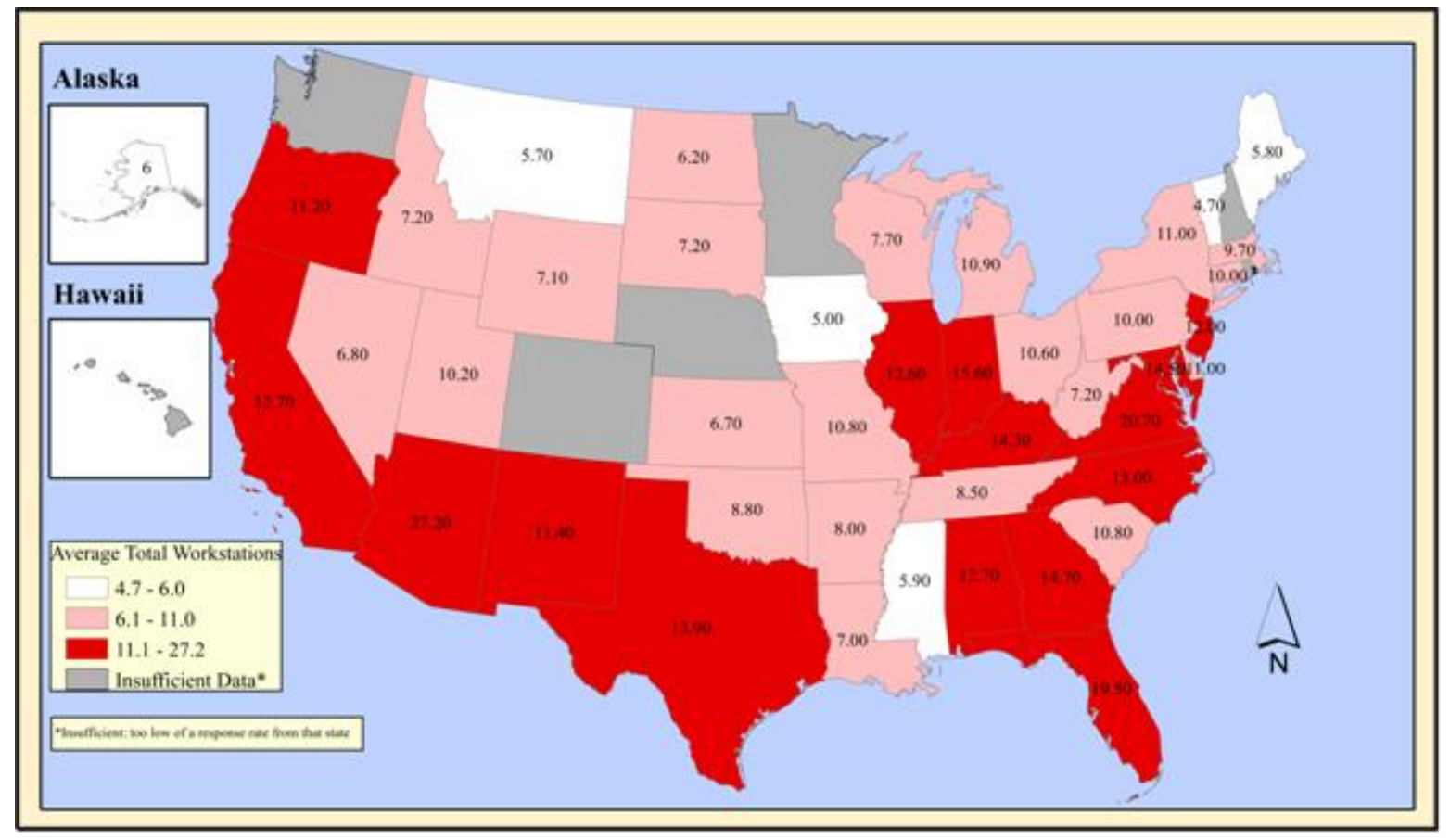

Figure 3. Average Number of Public Access Workstations by State (2007)

The practical lessons learned from this exploratory use of GIS in displaying national survey data include:

- Interval data collection makes mapping problematic,

- States do not like being left "off the map," and

- State level data may be misleading.

For interval data in this study, states were assigned the number that reflected the majority of responses; however, several states did not have one response that represented 50 percent or more of survey respondents. Therefore, these states were mapped as having "insufficient data" (See Figure 3). This may have been confusing for readers because the data were available, but collected in a manner not conducive to mapping. When these data collection decisions are made, researchers should be aware of these issues and plan to collect data that will be more conducive to mapping, such as ordinal or nominal data. If researchers are planning to analyze and map their data via GIS, they should consider mapping principles regarding different types of data when designing data collection instruments and procedures.

The study team hoped that the states left "off the map" because of insufficient data would have increased response rates in subsequent years of the survey. The idea was that states that would see a map without their data would use this as an incentive to increase their response rates to get "on the map" in the future. However, is it possible that being a state "off the map" due to insufficient data might be preferable than being "on the map" in the bottom quartile for certain variables. Still, the authors believe that this tactic is more beneficial than harmful. 
In the Ask a Librarian study described earlier, MLC level granularity helped to display statewide coverage and mask missing counties of service, and in the Public Libraries and the Internet 2007 study, the state level granularity hides pockets of lower connectivity and disparity of total public access workstations between different regions within each state. Unfortunately, reporting data at higher levels of granularity (i.e., smaller geographic regions, such as counties) hides actual gaps in service to individuals and makes it difficult to achieve the objective results that may reveal the actual levels of service across the nation (Mandel, Bishop, McClure, Bertot, \& Jaeger, 2010). In addition, the survey is a sample and not a census of libraries; therefore, at lower levels of granularity (i.e., larger geographic regions, such as states) disparities in variables appear, but this is not necessarily because of actual gaps in service. It may, in fact, represent gaps in response rates.

\section{Needs Assessment of Florida Public Library E-government and Emergency/Disaster Management Broadband-enabled Services}

With the practical lessons learned from the two prior projects, the Information Institute again decided to utilize GIS when the opportunity arose to spatially analyze and display the locations of public libraries' connectivity around the state of Florida. At the county level of granularity, actual disparities could be displayed around the state. The Bill \& Melinda Gates Foundation Florida public library technology dataset (2009) made available from the State Library \& Archives of Florida provided a census of broadband connection variables for the public libraries in Florida. The study team linked the data to library locations, thereby allowing for the display of attribute (i.e., descriptive) data by library, including maps showing the ISPs. However, the Information Institute felt that county-level maps might be easier for users to read. Accordingly, the study team spatially joined the library's average connection values with county shapefiles allowing for the creation of maps displaying connectivity speed and cost for Florida libraries by county.

The findings from the needs assessment showed a wide variation among connectivity speeds and costs across the state of Florida, as well as from region to region. When viewed aggregated by county, the public library data showed variation in connectivity speeds and costs across the state; in particular, less populated counties tend to show slower connectivity speeds and higher average costs than urban counties. Figure 4 shows the great variation in annual connection costs around the state. Figure 5 shows similar chaotic variation in average connection speeds. These findings were presented in state and regional maps and additional discussion of findings exists in a much larger report (McClure et al., 2009). 


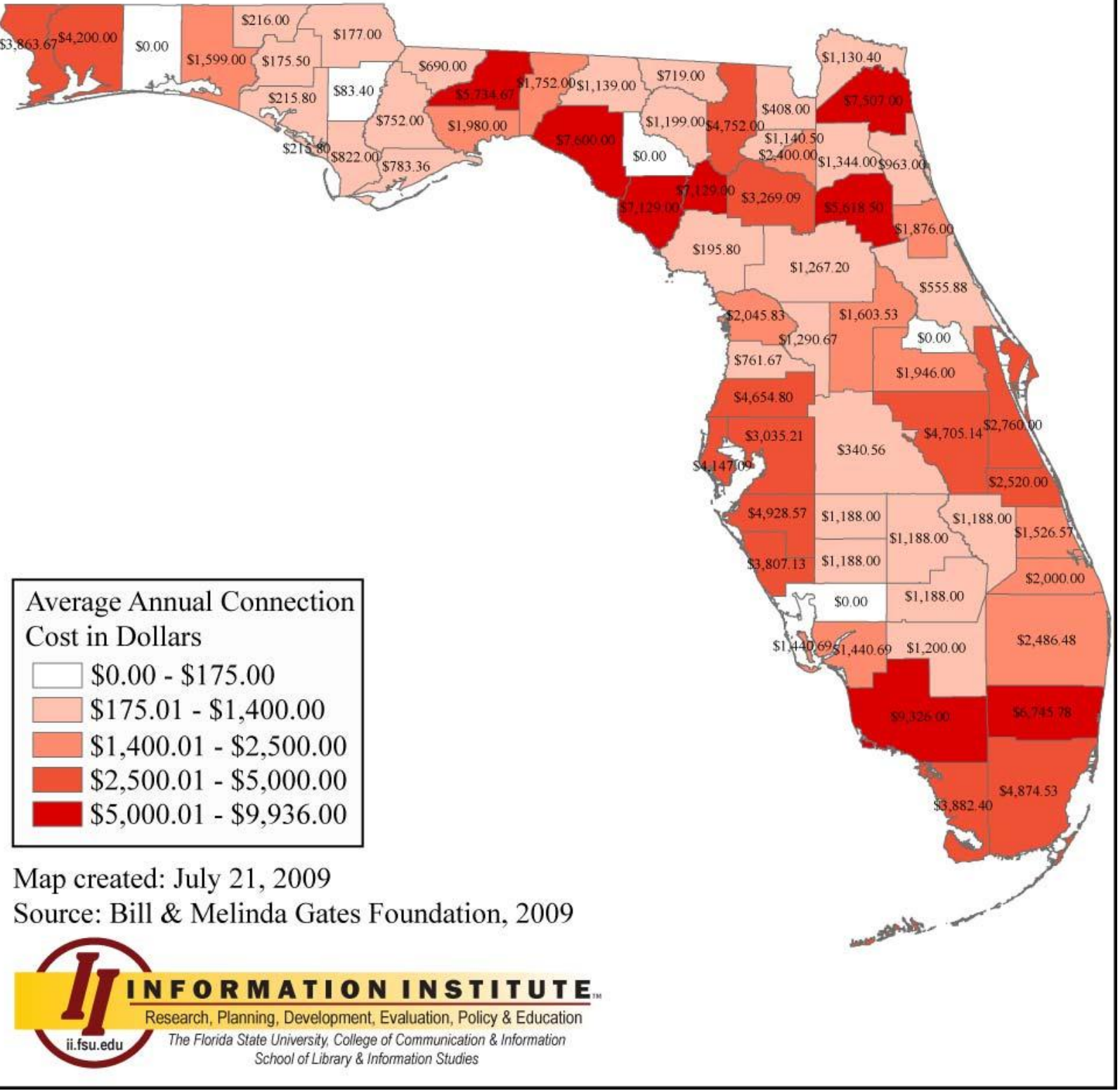

Figure 4. Average Annual Connection Cost for All Public Library Outlets by County: Florida 2009 


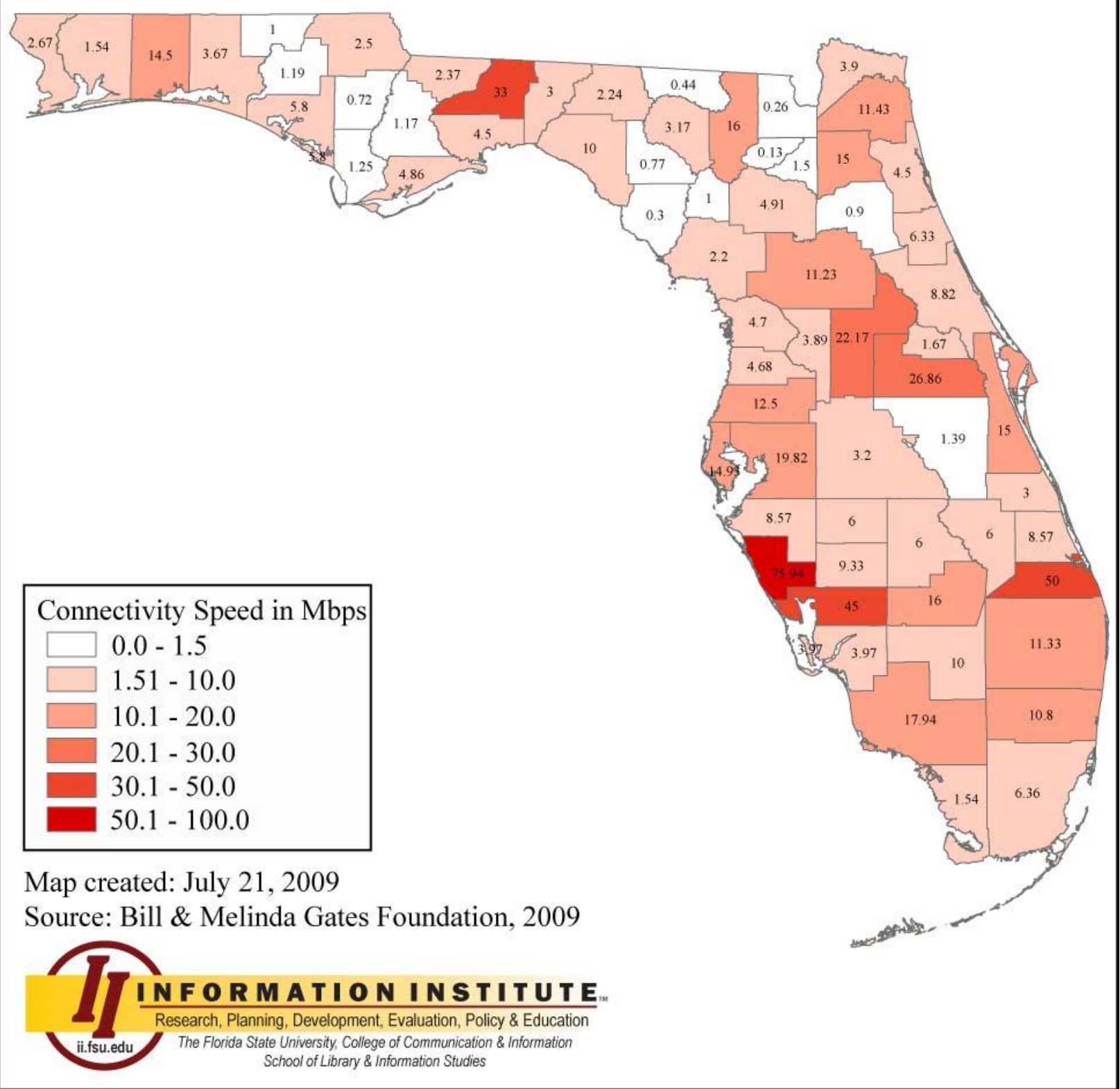

Figure 5. Average Connectivity for All Public Library Outlets by County: Florida 2009

With outlet level data, county level granularity was possible and comparisons across the state could be made at a glance. The practical lessons learned from this study include:

- Making data public can bring attention to significant disparities in costs and connectivity, which may have political ramifications for the institutions involved in the study,

- Many stakeholders may understand data better in a map compared to reading long reports and numerous tables (Dunn, 1990), and 
- For non-GIS experts, complex maps showing multiple variables are not useful tools for visualizing data and instead, researchers should employ multiple, simple maps to convey multiple variables, rather than a single map that can confuse readers.

Prior to making these results public, public libraries did not know if their connection speeds and costs were typical or outrageous compared to others around the state. Clearly, the competitive intelligence of keeping costs and speeds confidential benefits ISPs. However, two-thirds of public libraries report being the only provider of free public access to computers and the Internet in their communities (Bertot, Langa, Grimes, Sigler, \& Simmons, 2010). Therefore, it may be in the best interest of these communities relying on public libraries for free public Internet access if these vital anchor institutions can receive comparable connection speeds at reasonable costs.

Without these maps displaying disparities in space, the inequities for public libraries with Internet service are not as apparent. All stakeholders involved could view the results of the Florida public library technology data more easily in a map compared to having to read long reports and other visualizations of the data, such as tables. Most stakeholders do not usually use GIS or view projected spatial data. Therefore, a simple map limited to one variable and five ranges allows novice users to more easily discern the results than a complex map with multiple variables and a larger number of ranges of data. Libraries around the U.S. and elsewhere can employ GIS similarly to evaluate their own Internet connection situations.

\section{Issues Impacting the Use of GIS in LIS Research}

The three Information Institute projects described here with the literature review by Bishop and Mandel (2010) indicate a number of issues and next steps for researchers interested in using GIS as a tool for LIS research. A few key issues are discussed below, with suggestions for mitigating the issues. This discussion is followed by next steps for LIS researchers and the general LIS community.

\section{Methodological Issues}

As noted previously, interval data can be difficult to map appropriately and effectively, and the same is true of some qualitative data such as interview responses, observations, etc. LIS researchers who intend to analyze and display their data using GIS need to consider these issues when planning data collection efforts to ensure the collection of mappable data. One possible solution for this issue is for researchers to conduct pilot studies where they collect a small portion of data, enter that into a GIS, analyze and map it, and determine the effectiveness of mapping that data. Then the researchers could reevaluate their data collection strategies to ensure they are collecting mappable data.

\section{Cost Issues}

GIS can have many associated costs, including (1) the actual cost of GIS software, which, depending on the brand, can be quite expensive; (2) the time required to enter, analyze, and map the data; and (3) the expertise required to create effective and appropriate maps. Using open source GIS software, for example MapWindow (www.mapwindow.org) or GoogleMaps (http://maps.google.com), can mitigate some of these costs. Open source GIS software provide varying degrees of flexibility with regard to how data can be entered in a database, analyzed, and mapped. Therefore, the type of open source GIS chosen predicates what can and cannot be

$\operatorname{Pg} 13$ 
accomplished. For example, GoogleMaps only permits the creation of maps of locations on Earth, such as cities, towns, counties, etc., whereas MapWindow allows the creation of a map for location on Earth as well as maps of building interiors or other spaces.

\section{Educational Issues}

In addition to actual costs of the GIS software and licensing fees, using GIS requires substantial time and expertise on the part of the researcher. Entering data into a GIS database and then analyzing and visualizing that data is a time-consuming process. This process also requires a researcher with some background and skills in geography, cartography, GIS, databases, and graphic design. With over 400 programs offering geospatial technology education in the United States, many of which are available online (For more information, see: http://geotechcenter.org/STUDENTS/Locateprogram.aspx) and open source GIS products becoming more user-friendly, researchers have greater access to these GIS skills and software than before. Although it is helpful for a researcher to have some background in these areas, open source products like Google Maps or Google Earth are bringing GIS to everyone, and LIS researchers who lack a background in geography or GIS can conduct basic analysis of population demographics or other data in Google Earth with minimal training.

\section{Political Issues}

Reporting research findings, especially those related to program evaluations, can be fraught with political consequences - for the institution where the research was conducted, for the researcher, for the agency funding the research, for stakeholder groups, etc. Using GIS to display research findings can exacerbate these political consequences because displaying findings on a map can more specifically tie data (positive or negative) to a specific location, thereby shining the spotlight on one location over another. Researchers need to be careful in how they report findings to avoid harm when possible to any participants in the research, and for researchers using GIS, this means considering the implications of disseminating maps that showcase extremely positive or negative outcomes at one location versus others.

Researchers and stakeholders also should be aware that individuals use spatial data subjectively to produce differing views of the same world (Monmonier, 2008). For example, a European or North Americans researcher might orient a map of the world with the Atlantic Ocean in the center whereas an Asian researcher might orient the map with the Pacific Ocean in the center. Researchers need to keep in mind this inherent bias and its effect on the readers of a map when findings are shared in the form of maps.

\section{Summary of Issues}

Taken together, the issues summarized for these three projects are the reasons why GIS have limited use as tools for compiling, analyzing, and displaying LIS research data. However, these issues can be mitigated through educational efforts - both for researchers wishing to utilize GIS and for stakeholders who need to be able to understand the maps created by those researchers, alternative GIS software products that are less costly and time-consuming to use, and development of more user-friendly GIS software packages. 


\section{Next Steps}

The authors wish to suggest some next steps for LIS researchers and educators to assist in advancing the use and application of GIS to LIS research. These next steps include:

- Education of LIS researchers and practitioners; Although open source GIS and several GIS educational programs are making GIS more accessible to a broad range of researchers (and practitioners) regardless of educational background, if LIS as a field wishes to encourage the use of GIS as a tool for LIS research, then LIS education should incorporate into existing LIS coursework the following topics - GIS, the basic principles of geography, organizing and locating spatial data, and some instruction on how to read and explain maps to stakeholders;

- Training of stakeholder groups: LIS researchers and practitioners who intend to display research and program evaluation findings via GIS need to train their stakeholders on the value of maps, as well as how to understand those maps and the data they convey, and this might be accomplished via informal training opportunities in libraries or other venues, such as libraries offering basic GIS and/or map reading courses as part of their existing technology training programs;

- Experimenting with open source GIS products: Open source GIS allow researchers to try analyzing their data using a GIS to see the effectiveness of GIS as analysis and visualization tools while becoming familiar with GIS software platforms, all without purchasing a costly proprietary site license, for example using MapWindow to create a map depicting the demographics of a library service area and local school curriculum to inform children's programming or using GeoDa (http://geodacenter.asu.edu/)to visualize the highest circulating portions of a library's collection; and

- Applications of GIS to additional research methods: Beyond the most common uses of GIS in LIS research discussed by Bishop and Mandel (in press), there are innovative possibilities for collecting data that LIS researchers can explore, such as the project Losing Libraries, which is mapping the different types of cuts faced by libraries in a given area (http://www.losinglibraries.org/) or using web analytics to identify the IP addresses of users of a digital library or other online service, then geocoding the IP addresses, and mapping the distribution of those users on a map.

These next steps are offered in the hope of encouraging LIS researchers to experiment with GIS as a data analysis and visualization tool, as well as encouraging the field of LIS to embrace GIS as a highly beneficial tool for displaying data to assist in decision-making.

\section{Conclusion}

This paper detailed three projects utilizing geographic information systems (GIS) for the assessment of public libraries. The benefits of GIS include the abilities to generate maps to convey more information than other means and to allow for spatial analyses of library services. In some instances, a map provides a snapshot of data that tells a story in a timelier manner than lengthy amounts of text or other visualizations of data. Viewing library data in space in the instances described here revealed the differences in virtual reference service coverage of users and staffing, public access workstations across the United States, and other connectivity variables at a state level. 
Beyond the more obvious practical lessons learned, such as maps are popular with librarians and multiple-variable maps are too complicated for novice map readers to understand, these projects offered several other issues for consideration, including problems of geocoding from IP addresses, challenges of mapping interval data, and the complicated politics of any assessment. Other issues with using GIS for LIS research include the costs of GIS and the required expertise to utilize GIS effectively and appropriately.

Overall, the projects discussed here are offered as examples of assessment projects that utilized and benefited from GIS. Using GIS as analytical and visualization tools for the projects discussed here facilitated the Information Institute's understanding of the data, as well as allowing analyses across counties, regions, and states. Ultimately, the authors hope that the lessons they learned from incorporating GIS as part of multi-method data collection strategies can be applied to other LIS research. GIS are not as complicated to use as is commonly believed. The advances in open source GIS, particularly the popular Google Maps and Google Earth, and movements outside of the traditional GIS community, such as volunteered geographic information (VGI) and public participation of GIS (PPGIS) are bringing GIS into the hands of a broader range of researchers and citizens (Sui, 2007). LIS researchers should embrace GIS for its benefits and explore the possibilities GIS offer for analyzing and visualizing a variety of data.

\section{Acknowledgement}

The authors wish to acknowledge the generosity and support of the agencies that funded the three research projects described in this paper, including the Bill \& Melinda Gates Foundation and the State Library \& Archives of Florida. The authors also sincerely appreciate the assistance of all the staff at the Information Institute who contributed to these projects.

\section{References}

Bertot, J. C., Langa, L. A., Grimes, J. M., Sigler, K., \& Simmons, S. N. (2010). 2009-2010 Public library funding and technology access survey: Survey results and findings. College Park, MD: Center for Library and Information Innovation. Retrieved from http://www.ala.org/

Bertot, J. C., \& McClure, C. R. (1998a). Moving toward more effective public Internet access: The 1998 National Survey of Public Library Outlet Internet Connectivity. Washington, D.C.: National Commission on Libraries and Information Science. Retrieved from http://www.ii.fsu.edu/content/view/full/15365

Bertot, J. C., \& McClure, C. R. (1998b). The 1998 National Survey of U.S. Public Library Outlet Internet Connectivity: Final report. Washington, D.C.: National Commission on Libraries and Information Science. Retrieved from http://surface.syr.edu/ischool_other/54/

Bertot, J. C., \& McClure, C. R. (2000). Public Libraries and the Internet 2000: Summary findings and tables. Washington, D.C.: National Commission on Libraries and Information Science. Retrieved from http://www.ii.fsu.edu/content/view/full/15362 
Bertot, J. C., \& McClure, C. R. (2002). Public Libraries and the Internet 2002: Internet connectivity and networked services. Retrieved from http://www.ii.fsu.edu/content/view/full/15237

Bertot, J. C., McClure, C. R., Barton, K., Thomas, S., \& McGilvray, J. (2007). Public libraries and the Internet 2007: Survey results and findings. Tallahassee, FL: Information Use Management and Policy Institute. Retrieved from http://ii.fsu.edu/content/view/full/15164

Bertot, J. C., McClure, C. R., \& Fletcher, P. D. (1997). The 1997 National Survey of U.S. Public Libraries and the Internet: Final report. Washington, D.C.: American Library Association, Office for Information Technology Policy. Retrieved from http://www.ii.fsu.edu/content/view/full/15379

Bertot, J. C., McClure, C. R., \& Jaeger, P. T. (2004). Public Libraries and the Internet 2004: Survey results and findings. Tallahassee, FL: Information Use Management and Policy Institute. Retrieved from http://www.ii.fsu.edu/content/view/full/15216

Bertot, J. C., McClure, C. R., \& Jaeger, P. T. (2006). Public Libraries and the Internet 2006: Survey results and findings. Tallahassee, FL: Information Use Management and Policy Institute. Retrieved February 17, 2010, from http://www.ii.fsu.edu/content/view/full/15176

Bertot, J., McClure, C., \& Ryan, J. (2001). Statistics and performance measures for public library networked services. Chicago, IL: American Library Association.

Bertot, J. C., McClure, C. R., Wright, C. B, Jensen, E., \& Thomas, S. (2008). Public Libraries and the Internet 2008: Survey results and findings. Tallahassee, FL: Information Use Management and Policy Institute. Retrieved from http://www.ii.fsu.edu/content/view/full/15153

Bertot, J. C., McClure, C. R., Wright, C. B, Jensen, E., \& Thomas, S. (2009). Public Libraries and the Internet 2009: Survey results and findings. College Park, MD: Center for Library \& Information Innovation. Retrieved from http://www.ii.fsu.edu/content/view/full/17025

Bertot, J. C., McClure, C. R., \& Zweizig, D. L. (1996). The 1996 National Survey of Public Libraries and the Internet: Progress and issues. Washington, D.C.: National Commission on Libraries and Information Science. Retrieved from http://www.eric.ed.gov/ERICWebPortal/detail?accno=ED398932

Bishop, B. W., \& Mandel, L. H. (2010). Utilizing geographic information systems (GIS) in library research. Library Hi Tech, 28(4), 536-547.

Dunn, R. (1990). Rita Dunn answers questions on learning styles. Educational Leadership, 48, 15-19. 
Mandel, L. H., Bishop, B. W., McClure, C. R., Bertot, J. C., \& Jaeger, P. T. (2010). Broadband for public libraries: Importance, issues, and research needs. Government Information Quarterly, 27(3), 280-291. doi:10.1016/j.giq.2010.02.004

McClure, C. R., Bertot, J. C., \& Zweizig, D. L. (1994). Public Libraries and the Internet: Study results, policy issues, and recommendations. Washington, D.C.: National Commission on Libraries and Information Science. Retrieved from http://www.eric.ed.gov/ERICWebPortal/detail?accno=ED371768

McClure, C. R., Ryan, J., Mandel, L. H., Snead, J. T., \& Bishop, B. W. (2009). Needs assessment of Florida public library E-Government and emergency/disaster management broadband services. Tallahassee, FL: Information Use Management and Policy Institute. Retrieved from http://ii.fsu.edu/content/download/18354/118602

Mon, L., Bishop, B. W., McClure, C. R., McGilvray, J., Most, L., Milas, T. P., \& Snead, J. T. (2007). Who's asking? Geography and demographics of Florida's Ask-a-Librarian service. Tallahassee, FL: Information Use Management and Policy Institute.

Mon, L., Bishop, B.W., McClure, C.R., McGilvray, J., Most, L., Milas, T.P., \& Snead, J.T. (2009). The geography of virtual questioning. Library Quarterly, 79(4), 393-420. doi:10.1086/605381

Monmonier, M. (2008). Web cartography and the dissemination of cartographic information about coastal inundation and sea level rise. In M. P. Peterson (Ed.), International perspectives on maps and the Internet (pp. 48-72). Berlin: Springer-Verlag.

Sui, D. Z. (2008). The wikification of GIS and its consequences: Or Angelina Jolie's new tattoo and the future of GIS. Computers, Environment and Urban Systems, 32(1), 1-5. doi:10.1016/j.compenvurbsys.2007.12.001

United Nations, Department of Economic and Social Affairs, Statistics Division. (2000). Handbook on geographical information systems and mapping. New York: United Nations. 